\title{
Evaluation of hemodynamic changes in nonarteritic anterior ischemic optic neuropathy using multimodality imaging
}

\author{
Hongyang $\mathrm{Li}^{1} \wedge$, Jiao Sun ${ }^{1}$, Huihui Wang ${ }^{2}$, Yanling Wang ${ }^{1}$, Zhenchang Wang ${ }^{2}, \mathrm{Jing}^{\mathrm{Li}^{2} \wedge}$ \\ ${ }^{1}$ Department of Ophthalmology, Beijing Friendship Hospital, Capital Medical University, Beijing, China; ${ }^{2}$ Department of Radiology, Beijing \\ Friendship Hospital, Capital Medical University, Beijing, China
}

Correspondence to: Jing Li, PhD. Department of Radiology, Beijing Friendship Hospital, Capital Medical University, No. 95 Yong'an Road, Xicheng District, Beijing 100050, China. Email: faraway_sweet@outlook.com or lijingxbhtr@163.com.

Background: Nonarteritic anterior ischemic optic neuropathy (NAION) patients experience hypoperfusion in the short posterior ciliary arteries (SPCAs), however, the cause of hypo-perfusion is unclear. Real-time dynamic hemodynamic observations may provide clues into specific NAION pathogenic mechanisms. We aim to analyze hemodynamic changes occurring in NAION using multimodality imaging. Our specific focus is identifying pathogenic mechanisms underlying SPCA insufficiency in NAION.

Methods: Three-dimensional arterial spin labeling (3D ASL) magnetic resonance imaging (MRI) and three-dimensional time-of-flight (3D-TOF) magnetic resonance angiography (MRA) were performed on 25 NAION patients (50 eyes) and 22 (44 eyes) normal cases were recruited. The diameter of the initial part of the ophthalmic artery and internal carotid artery siphon were measured using MRA. Blood vessel identification and blood flow (BF) were detected using 3D ASL MRI. We measured BF values of the optic nerve head $(\mathrm{ONH})$ region of the retina/choroid complex, optic nerve $(\mathrm{ON})$, temporal lobe, and occipital lobe.

Results: We studied 32 NAION affected eyes, 18 NAION uninvolved eyes, and 44 normal eyes. Diameter of the initial part of ophthalmic artery in the NAION affected eyes was significantly larger than the uninvolved eyes $(\mathrm{P}=0.026)$. Diameter of the NAION eyes was $1.33 \pm 0.19 \mathrm{~mm}$ [mean \pm standard deviation (SD)], uninvolved eyes were $1.15 \pm 0.21 \mathrm{~mm}$. At a photolabeling delay times (PLD) of 1,500 and 2,500 ms, BF of the $\mathrm{ONH}$ and $\mathrm{ON}$ in NAION affected eyes was significantly less than uninvolved and normal eyes (pONH $<0.001$ both at 1,500 and 2,500 ms, pON $<0.001$ and $\mathrm{pON}=0.001$ at 1,500 and 2,500 ms, respectively). $\mathrm{ONH}$ of uninvolved eyes was also significantly less than normal eyes. Additionally, BF of the ONH region correlated with temporal lobe $\mathrm{BF}$, with an $\mathrm{R}^{2}=0.3231$ and 0.2397 at 1,500 and 2,500 ms, respectively. BF of the ONH region also correlated with occipital lobe $\mathrm{BF}$, with an $\mathrm{R}^{2}=0.2534$ and 0.4397 at 1,500 and 2,500 ms, respectively. $\mathrm{ON}$ and temporal lobe $\mathrm{BF}$ also correlated, with an $\mathrm{R}^{2}=0.226$ and 0.1504 at 1,500 and 2,500 ms, respectively.

Conclusions: Abnormal hemodynamics of small cerebral vessels existed prior to the onset of NAION. A candidate mechanism underlying NAION appears to be transient insufficiency of blood supply and decompensation of ocular vascular regulation.

Keywords: Nonarteritic anterior ischemic optic neuropathy (NAION); three-dimensional arterial spin labeling (3D ASL); magnetic resonance angiography (MRA); blood flow (BF); vascular compensatory capacity

Submitted May 16, 2020. Accepted for publication Nov 23, 2020.

doi: 10.21037/qims-20-699

View this article at: http://dx.doi.org/10.21037/qims-20-699

^ ORCID: Jing Li, 0000-0003-1375-0890; Hongyang Li, 0000-0001-6786-2105. 


\section{Introduction}

Nonarteritic anterior ischemic optic neuropathy (NAION) is a severely disabling disease that can cause blindness. NAION incidence is on the rise yet $(1,2)$ pathogenic NAION mechanisms remain unclear (3). The most common risk factors for NAION development are high blood pressure, diabetes (4,5). Additional potential risk factors include hyperlipidemia, increased homocysteine, sleep apnoea, anti-cardiolipin antibody syndrome, ischemic heart disease, thyroid disease, peptic ulcer disease, nocturnal low blood pressure, blood loss, and cataract surgery (6-11). This extensive list remains the subject of scrutiny amongst in prior NAION literature (12).

Prior studies have shown that NAION patients experience hypo-perfusion in the short posterior ciliary arteries (SPCAs) (13). However, the cause of hypo-perfusion is unclear and prior work suggests that this hypo-perfusion could be the result of vasospasm, failure of ocular blood flow (BF) auto-regulation, venous occlusion, or atherosclerosis (14). Cerebral main vessel pathology is also thought to be associated with NAION. While one study found that patients with NAION have an increased risk of ischemic stroke or transient ischemic attack (15), another report by Park et al. suggested that NAION is not associated with a greater risk of stroke than in the general population (16). Others have also reported no significant difference in the degree of obstruction when comparing the internal carotid artery diameter of NAION affected and unaffected patients (17). Cerebral small vessel disease (SVD) is frequently present in patients with NAION compared to age and medical diagnosis-matched controls (18). NAION is also related to future physical disabilities secondary to stroke or parkinsonism, as well as future cognitive decline secondary to dementia $(19,20)$. Other studies have found that the unaffected eyes of NAION patients exhibit abnormalities compared to healthy patient eyes when examined using optical coherence tomography angiography (OCT-A) (21). This suggests that vascular changes in the eyes of NAION patients may occur prior to the changes in retinal thickness that are associated with early stages NAION. After reviewing the NAION literature, we hypothesized that NAION would belong to SVD, and chronic hypoperfusion and decompensation of small blood vessels maybe one of risk factors for development to NAION. Thus, real-time dynamic hemodynamic observations may provide clues into specific NAION pathogenic mechanisms. However, dynamic hemodynamic observations of the optic nerve $(\mathrm{ON})$ and optic nerve head $(\mathrm{ONH})$ is technically challenging.

Three-dimensional arterial spin labeling (3D ASL) is a recently developed non-invasive, non-contrast-enhanced MR perfusion imaging technology (22). Studies have revealed that a combination of a $3 \mathrm{D}$ ASL sequence with an ocular surface coil can successfully measure BF in the $\mathrm{ONH}$ region (23). To test our hypothesis that small blood vessel decompensation is a pathogenic NAION mechanism, we used multiple 3D ASL sequences with different photolabeling delay times (PLD) for imaging of $\mathrm{ONH}$, ON, temporal lobe, and occipital lobe. Short and long PLD provide differing insights as short PLD times can detect hypoperfusion abnormalities caused by vascular stenosis whereas long PLD times can evaluate actual perfusion levels and vascular compensatory capacity. Furthermore, three-dimensional time-of-flight (3D-TOF) magnetic resonance angiography (MRA) were used to detect changes in the diameter of large and medium vessels in the head and neck. Through a detailed analysis of NAION pathogenic mechanisms, we hope to provide guidance in imaging methodology that will aid in the clinical treatment of NAION.

\section{Methods}

\section{Study patient demographics}

A total of 25 patients with NAION were recruited from the ophthalmology department of Beijing Friendship Hospital at Capital Medical University in Beijing, China. Recruitment took place from May 2018 to May 2019 and patients meeting the inclusion criteria were offered participation in the study, which included consultation and outpatient follow-up visits at least 6 months. The patients with bilateral NAION were consecutively onset. The control group were recruited from ophthalmic clinic, the patients were complete ophthalmic examination, and rule out the ophthalmic diseases like keratopathy, glaucoma, uveitis, high myopia, vitreous-retina diseases, macular diseases, tumors and other diseases associate with optic neuropathy.

Diagnostic criteria for NAION included (24): (I) a history of sudden visual loss, typically experienced in the morning, with an absence of other ocular and neurologic diseases that may better explain the patient's visual symptoms, (II) optic disc edema at the onset of vision loss that was documented at least two ophthalmologists, (III) optic disc edema that spontaneously resolved within 2 to 
3 months, (IV) visual field defects associated with the optic disc in the affected eye, and (V) no neurologic or ocular disorder that could be the underlying cause of the optic disc edema and visual field defects.

Exclusion criteria included: (I) previous corticosteroid therapy or any other treatment for NAION, (II) arteritic anterior ischemic optic neuropathy (25), and (III) cranial CT, carotid artery doppler or cranial MRI showing a disease that would result in insufficiency in ophthalmic arterial blood supply, such as brain tumor compression and carotid artery stenosis.

Serum samples were drawn at the Examination Center for Biomedical Research of Beijing Friendship Hospital. Blood samples were collected as part of routine treatment for this study.

\section{Neuro-ophthalmology evaluation}

Ophthalmic examinations included slit lamp examination, pupillary reaction testing, noncontact intraocular pressure examination, and fundus examination by senior neuroophthalmologists. Visual acuity was examined using a standard table of vision logarithms at a distance of 5 meters. Patients unable to read any letters at one meter were further examined using finger counts, hand movements, or light perception. Visual field testing was performed using a Humphrey Field Analyzer (30-2 SITA, Humphrey 750i, Zeiss, Germany). OCT examinations were performed using enhanced depth imaging (EDI) and OCT (Spectralis; Heidelberg Engineering, Heidelberg, Germany).

\section{Magnetic resonance image acquisition}

Orbital MRI examination was conducted with a $3.0 \mathrm{~T}$ Philips scanner (Ingenia 3.0T; Philips Healthcare, Best, Netherlands) using the commercial body coil for transmission and a 16-channel head coil for reception. Head motion was minimized by using the manufacturer provided restraining foam pads. Subjects were asked to close their eyes to minimize any effects of deliberate eye movement during image acquisition. The baseline imaging protocol consisted of T1WI, T2WI and coronal T2-FLAIR sequences. Advanced sequences include ASL and headMRA. ASL was done using a three-dimensional pseudocontinuous arterial spin labeling sequence (3D-pCASL). Other instrumental parameters included a PLD of 1,500 and $2,500 \mathrm{~ms}$, a TE of $12 \mathrm{~ms}, \mathrm{FA}=90^{\circ}$, thickness $=3.5 \mathrm{~mm}$, NEX $=2$, for 20 imaging slices. The central location of the scan

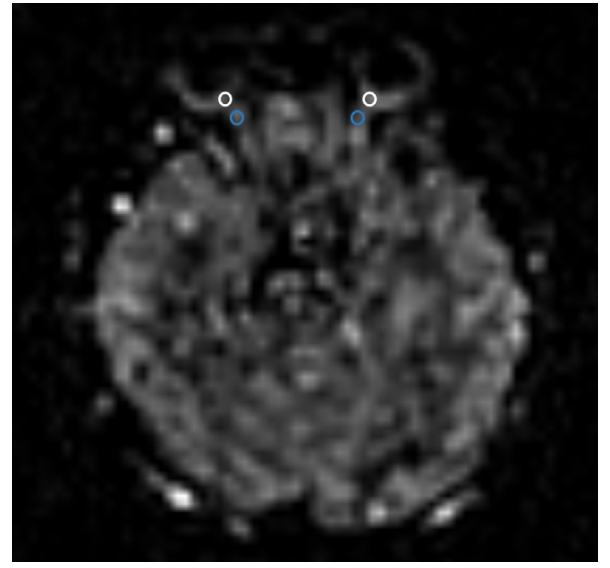

Figure 1 Regions of interest in axial slice for $\mathrm{ONH}$ and $\mathrm{ON}$. Bilateral ONH region of the retina/choroid complex (white ring), ON (bule ring) were drew. ONH, optic nerve head; ON, optic nerve.

was in optic papilla and the scan baseline was parallel to the ON. The cerebral blood flow (CBF) map was automatically derived from 3D-ASL images using the workstation (IteliiSpace Portal Release v7.0.4.20175). A 3D-TOF MRA sequence $(\mathrm{TE}=3.5 \mathrm{~ms}, \mathrm{TR}=19.0 \mathrm{~ms}$, thickness $=0.6 \mathrm{~mm}$, 156 slices, acquisition time approximately 4 minutes and 30 seconds) was used to visualize the internal carotid artery siphon, which is the initial part of ophthalmic artery.

\section{Measurement of BF and vessel diameter}

An anatomical image slice, centered on the $\mathrm{ON}$ of each subject, was selected as the target slice. An experienced neuroradiologist drew regions of interest in this slice and was blinded to the clinical data. BF was measured in each eye corresponding to the anatomical location of the bilateral ONH region of the retina/choroid complex, ON (Figure 1), temporal lobe, and occipital lobe. The initial part of ophthalmic artery diameter was measured on the NAION side and non-NAION region.

\section{Statistical analysis}

All reported values and error bars on graphs are written as mean \pm standard deviation (SD). Number of samples was calculated by PASS software (version 15.0), two sample $t$-tests allowing unequal variance module calculation, power $=0.9$. Cohort differences in age and BF values were analyzed using the Mann-Whitney and Kruskal-Wallis $\mathrm{H}(\mathrm{K})$ test. 
Table 1 Patient demographics and clinical characteristics

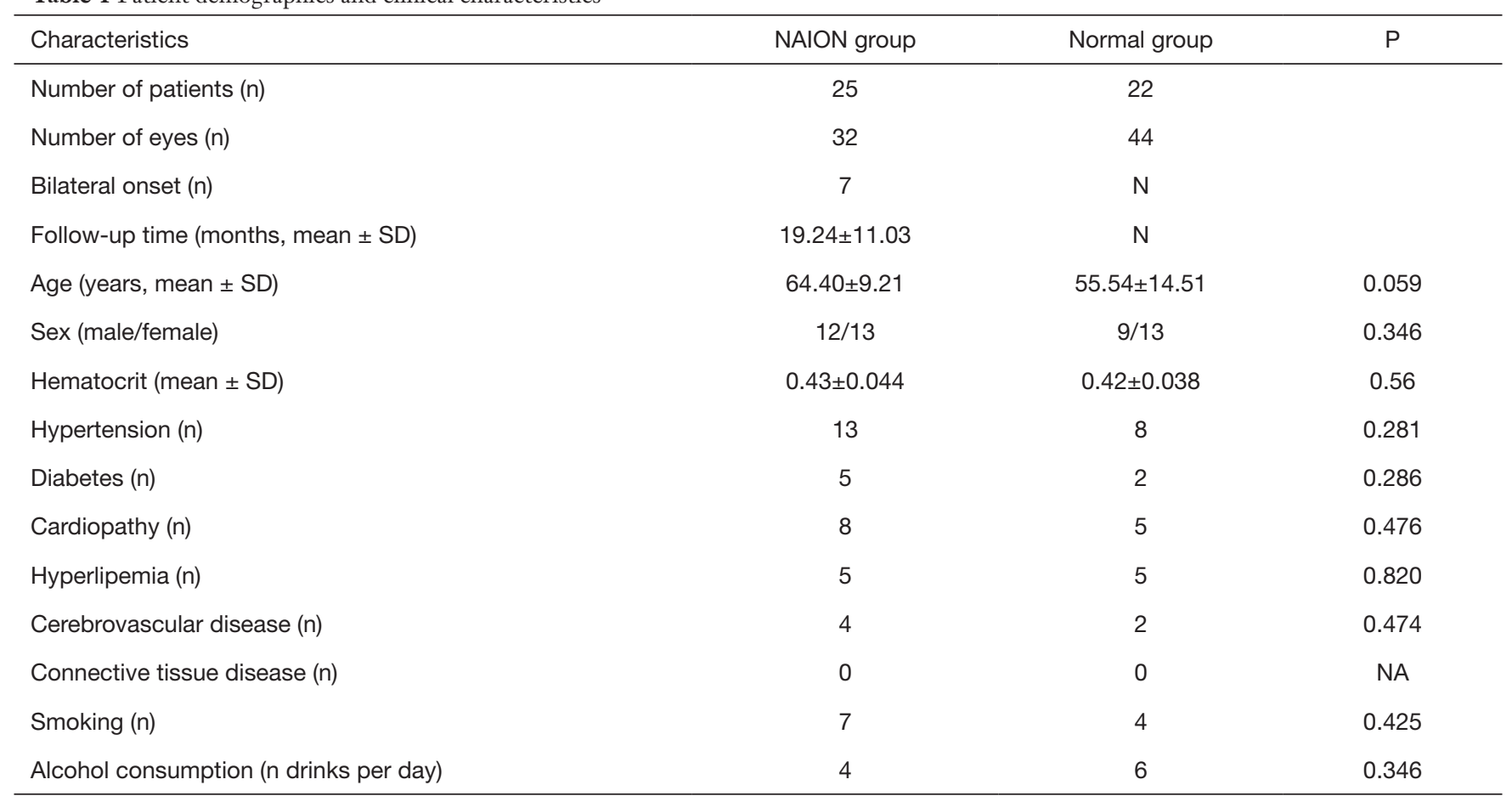

NAION, nonarteritic anterior ischemic optic neuropathy; SD, standard deviation; NA, not applicable.

Pearson $\chi^{2}$ tests or Fisher's exact test was used to control for gender and clinical symptoms involvement. Linear regression was used to analyze the correlation between two variables. All statistical analyses were performed using Statistical Package for the Social Sciences software V.19.0 (IBM Corporation). Statistical significance was defined as $\mathrm{P}<0.05$.

\section{Ethical approval and consent}

This study was approved by the BFH Ethics Committee and was conducted following the latest iteration of the Declaration of Helsinki (version: 2019-P2-201-01). Participants were given written informed consent (version V1.1/2019-09-16) before inclusion in the study.

\section{Results}

\section{Patient demographics and clinical characteristics}

Twenty-five patients (12 males and 13 females) had unilateral or bilateral NAION with a total of 32 involved eyes. Age at NAION diagnosis ranged from 45 to 80 $(64.40 \pm 9.21)$ years old. Comorbidities included 13 patients with hypertension, eight patients with cardiomyopathy, five patients with diabetes, five patients with hyperlipemia, and four patients with cerebrovascular disease. Table 1 summarizes the patient demographics and clinical characteristics. Eighteen eyes uninvolved eyes in patients with unilateral NAION were used as a negative control group. Twenty-two age and gender matched patients with no eye pathology (i.e., 44 eyes) were included as a healthy control group. Optic disc atrophy was evaluated by OCT, we divided the peripapillary retina never fiber layer (RNFL) into six regions. The peripapillary thickness of RNFL was $68.44 \pm 19.47 \mu \mathrm{m}$ in NAION eyes group and $99.39 \pm 20.48 \mu \mathrm{m}$ in uninvolved eyes group; the temporal superior thickness was $70.63 \pm 35.03 \mu \mathrm{m}$ in NAION eyes group and $118.83 \pm 38.91 \mu \mathrm{m}$ in uninvolved eyes group; the temporal thickness was $59.53 \pm 24.05 \mu \mathrm{m}$ in NAION eyes group and $64.61 \pm 15.71 \mu \mathrm{m}$ in uninvolved eyes group; the temporal inferior thickness was $100.78 \pm 46.11 \mu \mathrm{m}$ in NAION eyes group and $122.72 \pm 25.57 \mu \mathrm{m}$ in uninvolved eyes group; the nasal inferior thickness was $91.09 \pm 41.93 \mu \mathrm{m}$ in NAION eyes group and $137.50 \pm 46.10 \mu \mathrm{m}$ in uninvolved eyes group; the nasal thickness was $52.75 \pm 19.08 \mu \mathrm{m}$ in NAION eyes group and $80.44 \pm 22.85 \mu \mathrm{m}$ in uninvolved eyes group; the nasal superior thickness was $66.56 \pm 31.43 \mu \mathrm{m}$ in NAION 


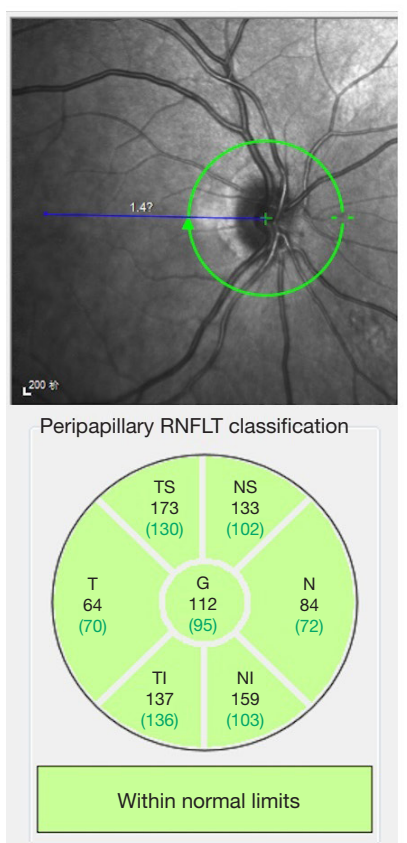

Retina nerve fiber layer (RNFL) thickness among different areas

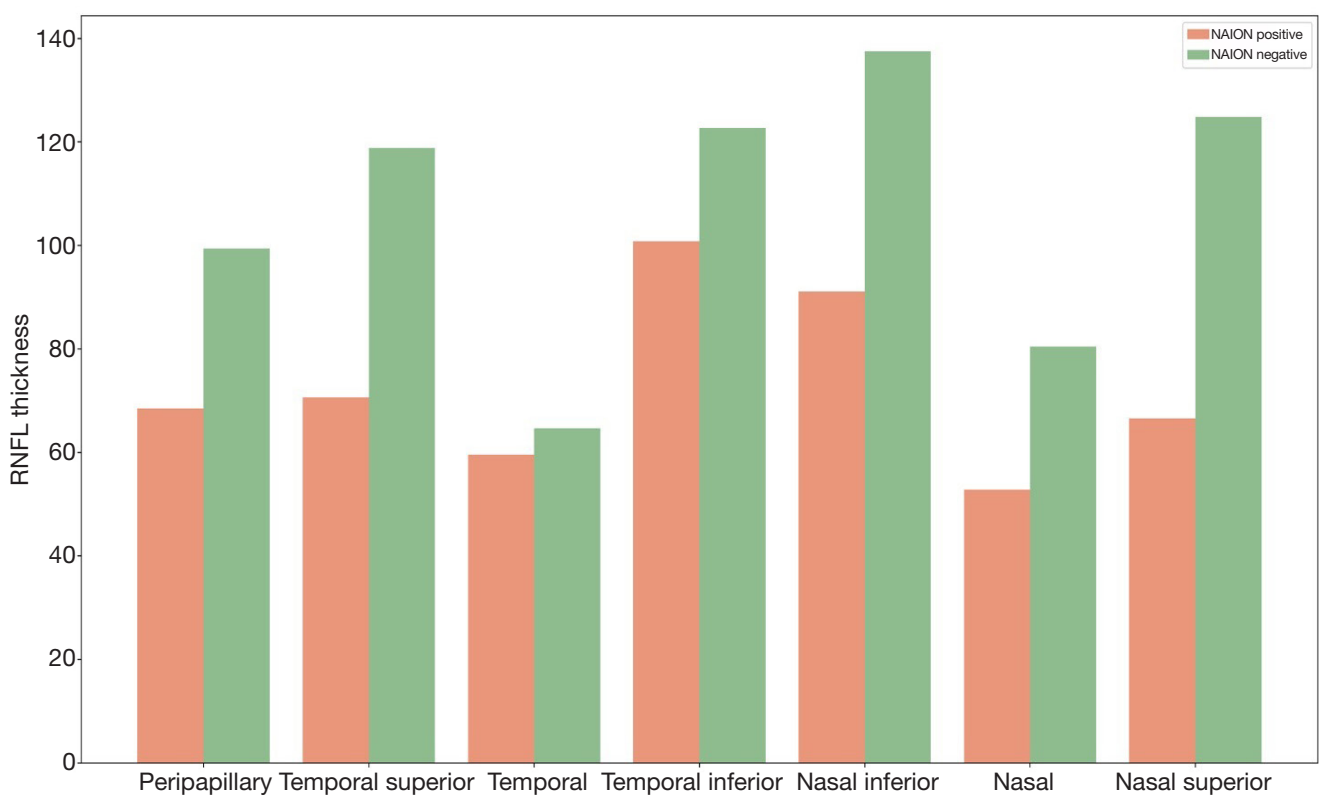

Figure 2 Peripapillary thickness of RNFL in different regions were tested by OCT. RNFL, retinal nerve fiber layer; OCT, optical coherence tomography.

eyes group and $124.83 \pm 51.20 \mu \mathrm{m}$ in uninvolved eyes group (Figure 2).

\section{$B F$ data of varying regions at distinct PLDs}

BF were measured through ASL MR imaging in both the short (1,500 ms) and long (2,500 ms) PLD (Figure 3). And we found that blood perfusion decreased in NAION affected severe eyes, when compared to mild eyes in both the short and long PLD from the lateral NAION patients (Figure 4). BF values for the $\mathrm{ONH}$ region of the retina/choroid and the $\mathrm{ON}$, temporal lobe, and occipital lobe regions were measured in all three groups and are summarized in Table 2.

Figure 5 illustrates $\mathrm{BF}$ data when using a short PLD (i.e., $1,500 \mathrm{~ms})$. BF values for the ONH region of the retina/ choroid were not significantly different between affected and unaffected eyes in patients with NAION $(6.03 \pm 4.86 v s$. $8.14 \pm 6.02 \mathrm{~mL} / 100 \mathrm{~g} / \mathrm{min}, \mathrm{P}=0.888)$, however, NAION affected eyes had significantly less $\mathrm{BF}$ than normal eyes $(6.03 \pm 4.86$ vs. $16.88 \pm 8.44 \mathrm{~mL} / 100 \mathrm{~g} / \mathrm{min}, \mathrm{P}<0.001)$ as $\mathrm{did}$ uninvolved eyes compared to normal eyes $(8.14 \pm 6.02 \mathrm{vs}$. $16.88 \pm 8.44 \mathrm{~mL} / 100 \mathrm{~g} / \mathrm{min}, \mathrm{P}<0.001)$. BF values in the $\mathrm{ON}$ region were not significantly different between affected and unaffected eyes in patients with NAION $(6.29 \pm 5.53$ vs. $7.60 \pm 5.29 \mathrm{~mL} / 100 \mathrm{~g} / \mathrm{min}, \mathrm{P}=1.000$ ), however, as in the $\mathrm{ONH}$ region of the retina/choroid, NAION affected and uninvolved eyes had significantly less BF than normal eyes $(6.29 \pm 5.53$ and $7.60 \pm 5.29$ vs. $14.25 \pm 6.78 \mathrm{~mL} / 100 \mathrm{~g} / \mathrm{min}$, $\mathrm{P}<0.001$ and $\mathrm{P}=0.003$, respectively). $\mathrm{BF}$ values in the temporal lobe were significantly lower in NAION affected eyes compared to normal eyes $(9.39 \pm 6.02$ vs. $17.11 \pm$ $8.75 \mathrm{~mL} / 100 \mathrm{~g} / \mathrm{min}, \mathrm{P}<0.001$ ) however, no differences were observed between NAION affected and unaffected eyes $(9.39 \pm 6.02$ vs. $11.70 \pm 6.32 \mathrm{~mL} / 100 \mathrm{~g} / \mathrm{min}, \mathrm{P}=0.535)$ or unaffected eyes and normal eyes $(11.70 \pm 6.32$ vs. $17.11 \pm$ $8.75 \mathrm{~mL} / 100 \mathrm{~g} / \mathrm{min}, \mathrm{P}=0.102)$. BF values in the occipital lobe were significantly less for NAION affected and unaffected eyes compared to normal eyes $(9.23 \pm 6.89$ and $12.12 \pm 9.03$ vs. $18.37 \pm 10.23 \mathrm{~mL} / 100 \mathrm{~g} / \mathrm{min}, \mathrm{P}<0.001$ and $\mathrm{P}=0.021$, respectively). However, no occipital lobe $\mathrm{BF}$ difference was observed between NAION affected and unaffected eyes $(9.23 \pm 6.89$ vs. $12.12 \pm 9.03 \mathrm{~mL} / 100 \mathrm{~g} / \mathrm{min}, \mathrm{P}=1.000)$.

Figure 6 illustrates BF data when using a longer PLD (i.e., 2,500 ms). While $\mathrm{BF}$ values for the $\mathrm{ONH}$ region of the retina/choroid were similar for NAION affected and unaffected groups $(11.64 \pm 7.98 v s .12 .84 \pm 6.77 \mathrm{~mL} / 100 \mathrm{~g} / \mathrm{min}$, $\mathrm{P}=1.000$ ), both of these groups had significantly lower 

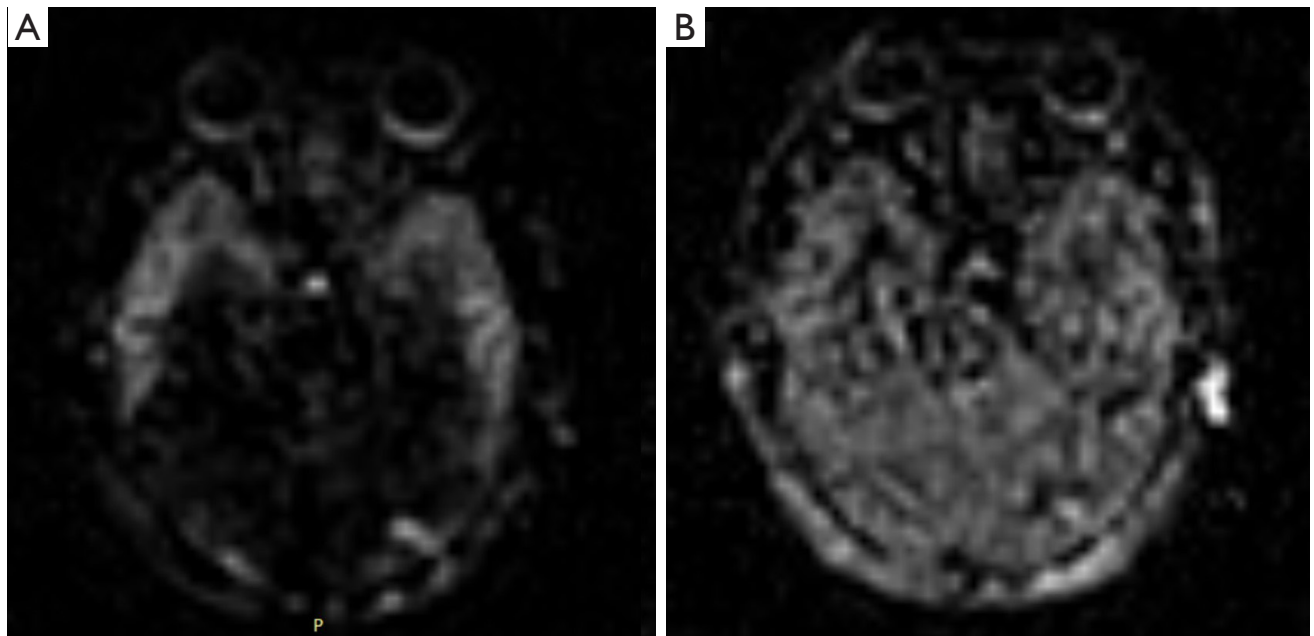

Figure 3 3D ASL MRI imaging at two different PLD times. (A) An axial slice imaging at PLD =1,500 ms; (B) axial slice imaging at PLD $=2,500 \mathrm{~ms}$. 3D ASL MRI, three-dimensional arterial spin labeling magnetic resonance imaging; PLD, photolabeling delay times.
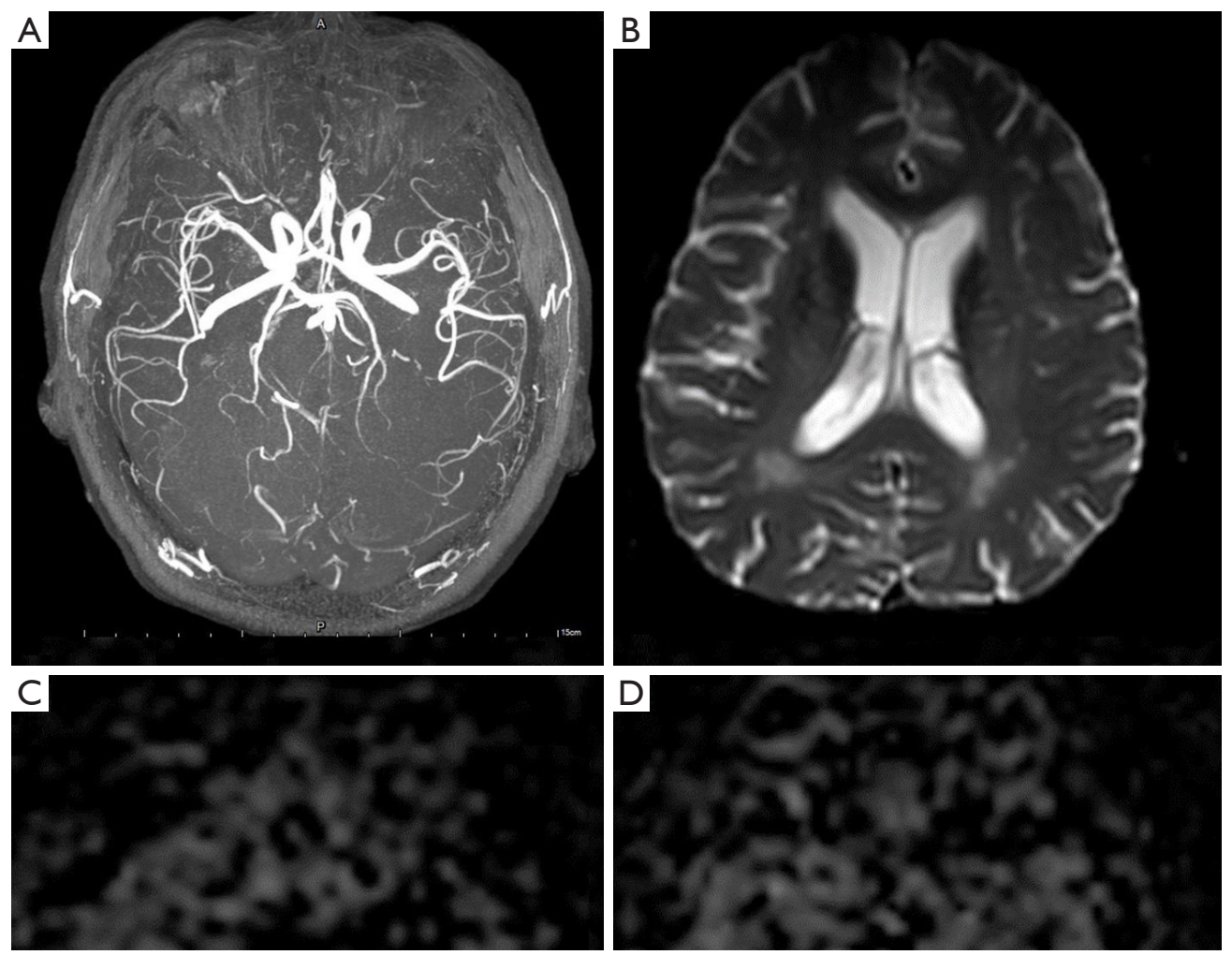

Figure 4 Multimodality MRI performed for bilateral NAION patient. Male, 66 years old, onset of left eye first, onset of right eye 3 weeks later. Vision acuity: $\mathrm{R}=0.8, \mathrm{~L}=0.3$. No obvious stenosis of intracranial blood vessels and ocular arteries though MRA (A). Axial slice T2WI showing multiple foci with long T2 signal in white matter (B). 3D ASL orbit MRI showing the retina/choroid complex in right eye with higher perfusion than left eye both in PLD =1,500 ms (C) and 2,500 ms (D). MRI, magnetic resonance imaging; NAION, nonarteritic anterior ischemic optic neuropathy; MRA, magnetic resonance angiography; PLD, photolabeling delay times. 
Table 2 Comparison of BF between NAION and normal cases (all listed as mean \pm SD)

\begin{tabular}{|c|c|c|c|c|c|c|c|}
\hline Regions for BF & NAION eyes & Uninvolved eyes & Normal eyes & $\mathrm{P}$ & $\mathrm{P} 1$ & $\mathrm{P} 2$ & P3 \\
\hline Optic disc & $6.03 \pm 4.86$ & $8.14 \pm 6.02$ & $16.88 \pm 8.44$ & $<0.001^{\star *}$ & 0.888 & $<0.001^{\star *}$ & $0.001^{* *}$ \\
\hline ON & $6.29 \pm 5.53$ & $7.60 \pm 5.29$ & $14.25 \pm 6.78$ & $<0.001^{\star \star}$ & 1.000 & $<0.001^{\star \star}$ & $0.003^{\star *}$ \\
\hline Temporal lobe & $9.39 \pm 6.02$ & $11.70 \pm 6.32$ & $17.11 \pm 8.75$ & $<0.001^{\star *}$ & 0.535 & $<0.001^{\star \star}$ & 0.102 \\
\hline \multicolumn{8}{|c|}{ PLD $=2,500 \mathrm{~ms}(\mathrm{~mL} / 100 \mathrm{~g} / \mathrm{min})$} \\
\hline Optic disc & $11.64 \pm 7.98$ & $12.84 \pm 6.77$ & $20.78 \pm 9.58$ & $<0.001^{\star \star}$ & 1.000 & $<0.001^{\star \star}$ & $0.012^{*}$ \\
\hline ON & $10.14 \pm 6.41$ & $12.71 \pm 6.54$ & $16.88 \pm 7.32$ & $0.001^{\star *}$ & 0.589 & $0.001^{\star \star}$ & 0.260 \\
\hline Temporal lobe & $18.45 \pm 7.20$ & $18.48 \pm 7.44$ & $26.36 \pm 8.68$ & $<0.001^{\star \star}$ & 1.000 & $<0.001^{\star \star}$ & $0.006^{\star \star}$ \\
\hline
\end{tabular}

P1: NAION eyes \& uninvolved eyes; P2: NAION eyes \& normal eyes; P3: uninvolved eyes \& normal eyes. *, P<0.05; ${ }^{* \star}, \mathrm{P}<0.01$. BF, blood flow; ON, optic nerve; NAION, nonarteritic anterior ischemic optic neuropathy; SD, standard deviation; PLD, photolabeling delay times.

BF values compared to normal eyes $(11.64 \pm 7.98$ and $12.84 \pm 6.77$ vs. $20.78 \pm 9.58 \mathrm{~mL} / 100 \mathrm{~g} / \mathrm{min}, \mathrm{P}<0.001$ and $\mathrm{P}=0.012$, respectively). $\mathrm{BF}$ values for the $\mathrm{ON}$ region were significantly less in NAION affected eyes when compared to normal eyes $(10.14 \pm 6.41$ vs. $16.88 \pm 7.32 \mathrm{~mL} / 100 \mathrm{~g} / \mathrm{min}$, $\mathrm{P}=0.001$ ), however no differences were observed between NAION affected eyes and normal eyes when compared to unaffected eyes $(10.14 \pm 6.41$ and $16.88 \pm 7.32$ vs. $12.71 \pm$ $6.54 \mathrm{~mL} / 100 \mathrm{~g} / \mathrm{min}, \mathrm{P}=0.589$ and $\mathrm{P}=0.260$, respectively). $\mathrm{BF}$ values in the temporal lobe were similar in NAION affected and unaffected eyes $(18.45 \pm 7.20 \mathrm{vs} .18 .48 \pm 7.44 \mathrm{~mL} / 100 \mathrm{~g} / \mathrm{min}$, $\mathrm{P}=1.000$ ) however both groups had significantly reduced $\mathrm{BF}$ compared to normal eyes $(18.45 \pm 7.20$ and $18.48 \pm 7.44$ vs. $26.36 \pm 8.68 \mathrm{~mL} / 100 \mathrm{~g} / \mathrm{min}, \mathrm{P}<0.001$ and $\mathrm{P}=0.006$, respectively). Occipital lobe $\mathrm{BF}$ values were also indistinguishable between NAION affected and unaffected eyes $(24.55 \pm 13.08$ vs. $27.62 \pm 11.38 \mathrm{~mL} / 100 \mathrm{~g} / \mathrm{min}, \mathrm{P}=1.000)$. However, normal eyes had significantly more $\mathrm{BF}$ than NAION affected eyes, yet not unaffected eyes $(33.48 \pm 12.69$ vs. $24.55 \pm 13.08$ and $27.62 \pm 11.38 \mathrm{~mL} / 100 \mathrm{~g} / \mathrm{min}, \mathrm{P}=0.03$ and $\mathrm{P}=0.134$, respectively).

\section{Correlation between ocular BF and cranial BF perfusion}

To assess whether a correlation existed between ocular BF and cranial $\mathrm{BF}$, we applied linear regression to measure changes in the retina/choroid, ON region, temporal lobe, and occipital lobe. At a PLD of 1,500 and 2,500 ms, there was a significant correlation between $\mathrm{BF}$ of the $\mathrm{ONH}$ region of the retina/choroid and temporal lobe $\left(\mathrm{R}^{2}=0.3231\right.$, $\mathrm{P}<0.001$ and $\mathrm{R}^{2}=0.2397, \mathrm{P}=0.005$ at 1,500 and $2,500 \mathrm{~ms}$, respectively). There was also a significant correlation between $\mathrm{BF}$ of the $\mathrm{ONH}$ region of the retina/choroid and occipital lobe $\left(\mathrm{R}^{2}=0.2534, \mathrm{P}<0.003\right.$ and $\mathrm{R}^{2}=0.4397, \mathrm{P}<0.001$ at 1,500 and 2,500 ms, respectively) (Figure 7). We also found a significant correlation between $\mathrm{BF}$ of the $\mathrm{ON}$ and the temporal lobe $\left(\mathrm{R}^{2}=0.226, \mathrm{P}=0.0059\right.$ and $\mathrm{R}^{2}=0.1504, \mathrm{P}=0.0283$ at 1,500 and $2,500 \mathrm{~ms}$, respectively). Similarly, a significant correlation existed between $\mathrm{BF}$ of the $\mathrm{ONH}$ region the retina/choroid and the occipital lobe $\left(\mathrm{R}^{2}=0.1861, \mathrm{P}<0.0137\right.$ and $\mathrm{R}^{2}=0.3012$, $\mathrm{P}=0.001$ at 1,500 and 2,500 ms, respectively) (Figure 8).

\section{Diameter changes in ocular and intracranial vessels}

MRA was used to investigate the diameter changes in ocular and intracranial vessels. Fifteen unilateral NAION patients received 3D TOF MRA, where the diameter of the initial part of ophthalmic artery and internal carotid artery siphon were compared between NAION affected and unaffected eyes. The diameter of the initial part of the ophthalmic artery in the NAION affected eyes was significantly larger than in unaffected eyes $(1.33 \pm 0.19 v s$. $1.15 \pm 0.21 \mathrm{~mm}, \mathrm{P}=0.026)$. However, there was no significant difference in the diameter of internal carotid artery siphon between NAION affected and unaffected eyes $(4.76 \pm 0.87$ vs. $4.86 \pm 0.63 \mathrm{~mm}, \mathrm{P}=0.603$ ) (Figure 9). 

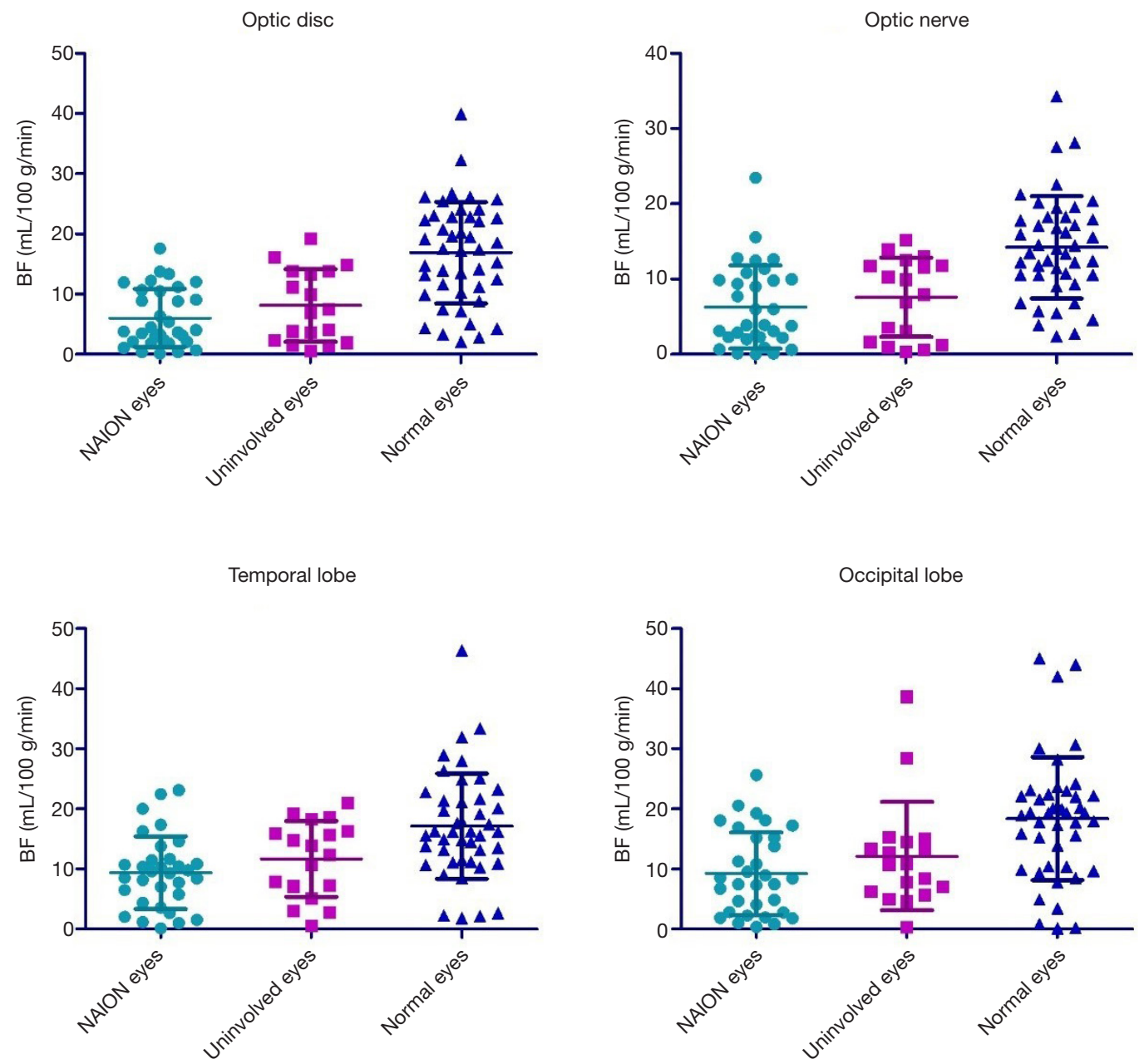

Figure 5 BF of ocular and intracranial organ among NAION eyes, uninvolved eyes and normal eyes using a PLD of 1,500 ms. BF, blood flow; NAION, nonarteritic anterior ischemic optic neuropathy; PLD, photolabeling delay times.

\section{Discussion}

The prevailing idea regarding pathogenic mechanisms in NAION is that there is hypoperfusion in the SPCAs (3). However, the etiology of this hypoperfusion remains unclear. We sought to address this question using real-time BF perfusion studies on NAION patients by examining bilateral ONH and the ON using multimodality MRI.

It is also unknown if perfusion of SPCAs is associated with the carotid and optic arteries. Previous NAION studies have reported decreased retrobulbar flow velocities and increased carotid wall thickness (26), yet the pathogenesis of NAION does not involve carotid artery stenosis in most patients (14). In our study, we used MRA to measure the diameter of the internal carotid siphon, which is associated with blood supply to the front of the brain. We found no significant differences among the NAION affected eyes and control groups, which aligns with prior reports that NAION is not associated with internal carotid artery stenosis (27). We did however, find that the diameter of the optic artery in NAION affected eyes was larger than NAION unaffected eyes. The $\mathrm{ONH}$ typically exhibits efficient $\mathrm{BF}$ autoregulation, likely due to an increase in vascular capacitance. However, multiple diseases can impair these autoregulatory mechanisms $(28,29)$. Prior studies in NAION suggest that the pathogenesis may be associated with impaired autoregulation of the microvascular supply (30). In this study we did not consider decompensation regulation would be the mechanism of NAION pathogenesis only by observing the dilation of optic artery like the prevision 
Optic disc

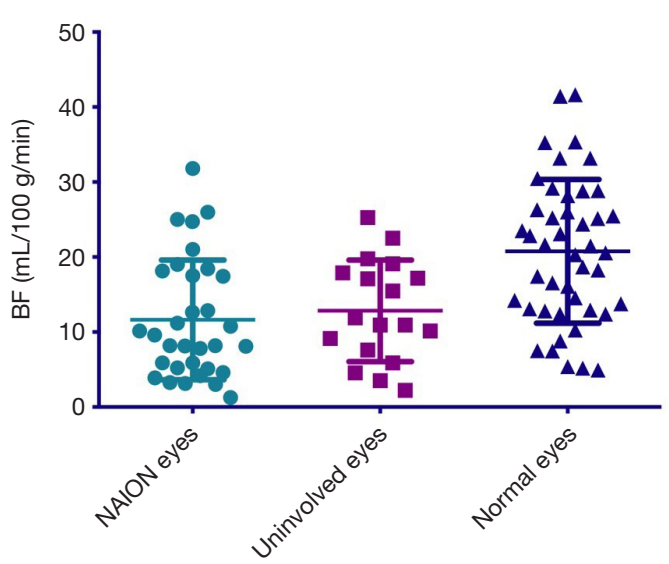

Temporal lobe

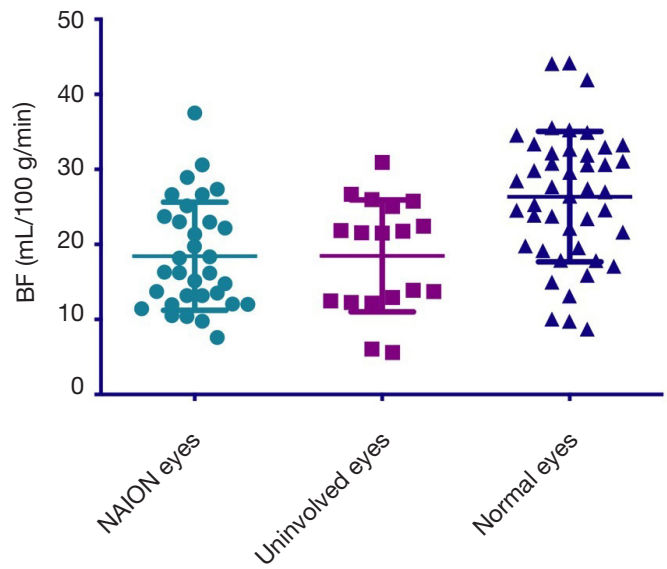

Optic nerve

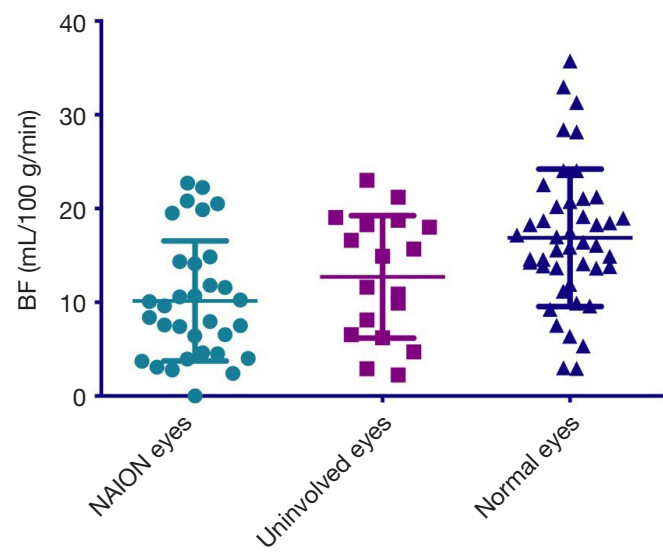

Occipital lobe

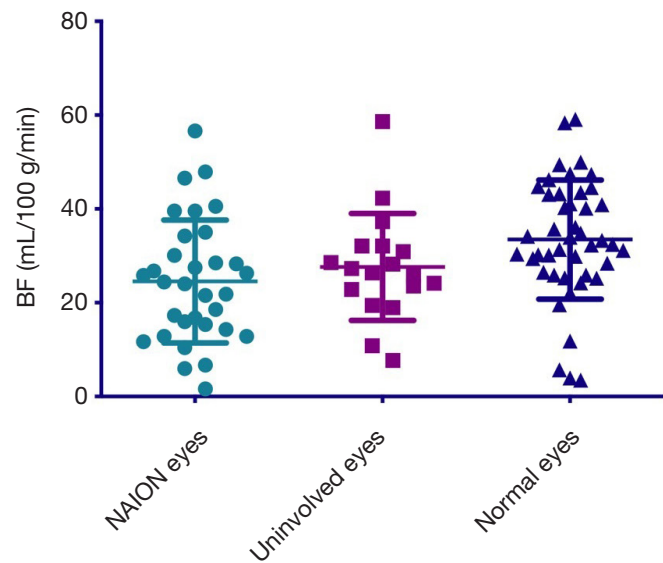

Figure 6 BF of ocular and intracranial regions among NAION eyes, uninvolved eyes and normal eyes using a PLD of 2,500 ms. BF, blood flow; NAION, nonarteritic anterior ischemic optic neuropathy; PLD, photolabeling delay times

study, but also BF perfusion of $\mathrm{ON}$ and optic disc were performed to identify the vascular filling state. We found that the optic artery dilation of NAION eyes were lager than the uninvolved eyes, and the BF perfusion became lower than the uninvolved eyes and controls. Thus, it is possible that decreased vasoconstriction and regulation of decompensation may be a mechanism of NAION pathogenesis.

Retrobulbar BF is useful for identifying possible NAION etiology. However, it is technically challenging to evaluate. Most ultrasound Doppler studies measure blood vessels that are fixedly selected but diseased vessels, such as those involved in NAION, are not selected. Therefore, ultrasound Doppler results are usually inadequate for evaluating changes in the microcirculation of the ONH (26). New technologies (e.g., laser Doppler flowmetry, blue-field entoptic, Laser Speckle Flowgraphy imaging) have been recently developed for examining the blood supply of the ocular wall $(31,32)$ (i.e., retina/choroid) yet are unable to clearly display the blood supply of the macula and ONH (22). Ciliary vessels have many branches in the posterior portion of the eye and measured parameters of different branches depend on sampling location. Measurement of the SPCAs is possible via Color Doppler Imaging, whereas challenging and variable in nature, it needs to improve detection range and detection accuracy. MRI were more and more used in the ocular diseases $(33,34), 3 \mathrm{D}$ ASL sequence is a newly developed, non-invasive, non-contrast-enhanced MR perfusion imaging technology (35). Recent studies have demonstrated that a combination of 3D ASL sequence 

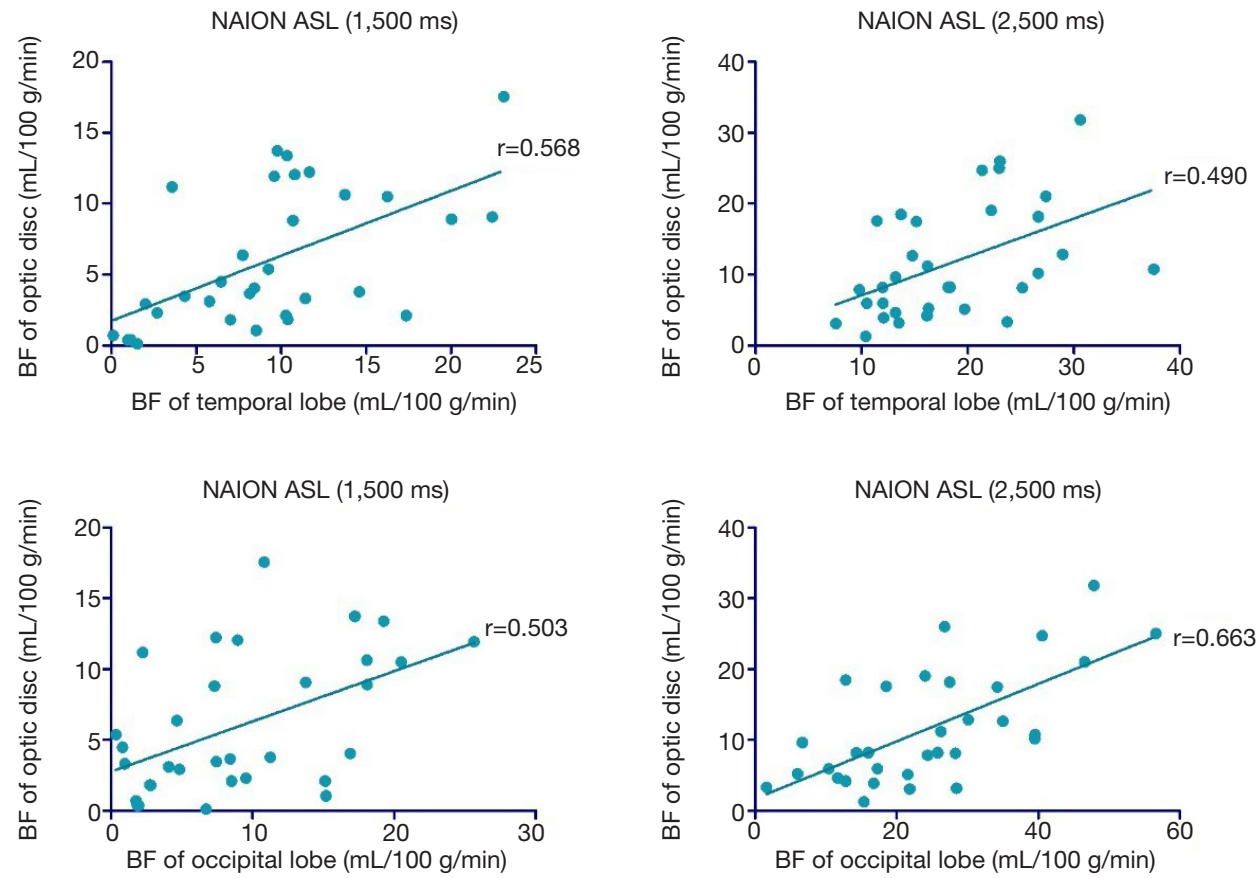

Figure 7 Correlation between BF in the $\mathrm{ONH}$ and cranial BF perfusion. BF, blood flow; ONH, optic nerve head.

NAION ASL (1,500 ms)
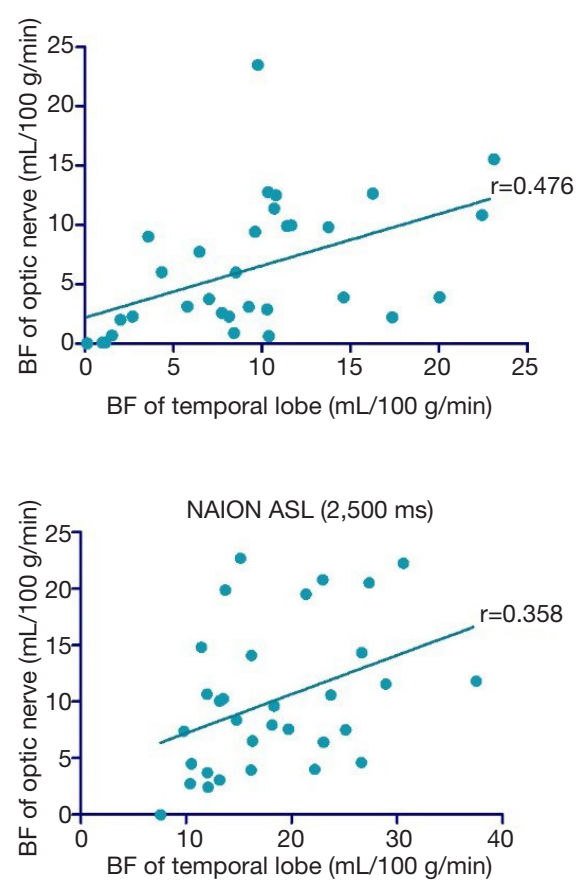

NAION ASL (1,500 ms)
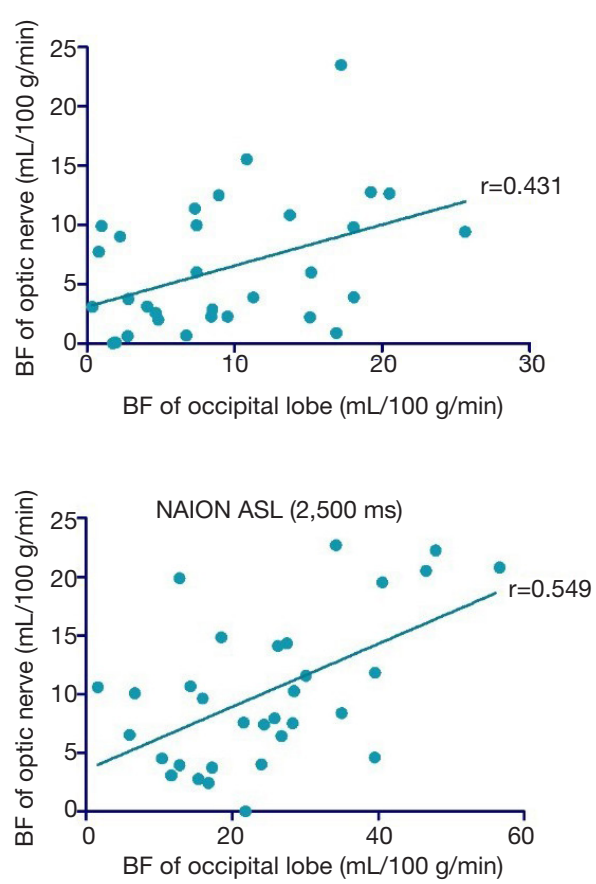

Figure 8 Correlation between ON and cranial BF perfusion. BF, blood flow; ON, optic nerve. 

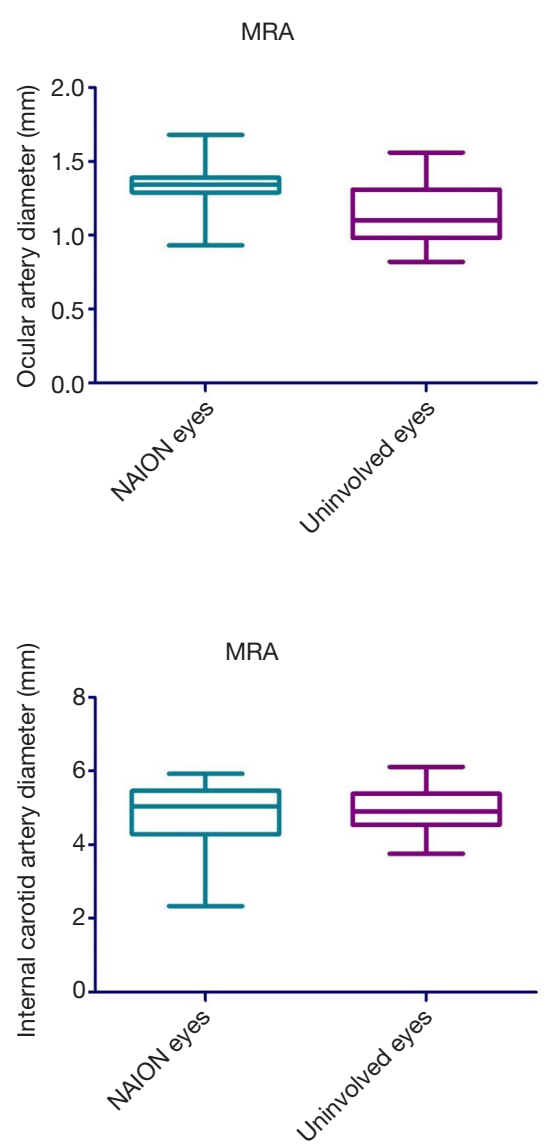

Figure 9 MRA evaluation of changes in ocular and intracranial vessel diameter. MRA, magnetic resonance angiography.

with an ocular surface coil can successfully measure BF in the $\mathrm{ONH}$ region (36). ASL has been used to test the $\mathrm{BF}$ perfusion in the retina, and $\mathrm{BF}$ in the $\mathrm{ONH}$ region decreases with age has been found (23). ASL has been used in clinical studies of retinal pigment degeneration to examine blood perfusion in retinal choroidal diseases and assess the severity of the disease (37). In our study we used 3D ASL to evaluate retrobulbar BF perfusion in NAION. We employed a short and long PLD in NAION affected and unaffected eyes (in the same patient when NAION was not bilateral), as well as healthy eyes. Short PLD is best suited for early detection of transient ischemic attack. Long PLD is preferred for assessing actual perfusion level and better reflects the level of compensation after ischemia (38). $\mathrm{ONH}$ and $\mathrm{ON}$ real-time perfusion decreased in NAION affected eyes, as evidenced by lower BF values when compared to normal eyes in both the short and long PLD. Some studies have presumed that NAION pathogenesis is due to a transient disruption in the circulation of the ONH, leading to hypoperfusion and ischemia $(39,40)$. Our study found that BF of the ON in NAION unaffected eyes was also different from healthy eyes, demonstrating that NAION patients have slow BF and insufficient blood supply to the ON. We believe this result proves that NAION has abnormal BF perfusion and lacks vascular compensation after hypoperfusion, resulting in permanent visual impairment.

It is also unclear from prior studies if cerebrovascular disease is a potential etiology of NAION. One prospective study of 406 patients with NAION found no increased risk of cerebrovascular disease or cardiac disease (5). Other studies have shown that the risk of cardiovascular and cerebrovascular events following NAION is similar to the risk of the general population $(41,42)$. Cerebral SVD is frequently present in patients with NAION (18) and SVD is thought to be the cause of hypoperfusion in NAION. To evaluate the association of NAION and SVD, we measured BF of the temporal and occipital lobes using ASL MRI and then looked for a correlation in vessel diameter between ocular and cerebral vessels. We found a significant correlation between the two, further implicating an association between cerebral SVD and NAION (18). We also found correlations ocular and cranial BF perfusion. Cranial BF was also lower when compared to healthy patients. Together these results are in line with prior studies suggesting that the hypoperfusion of SPCA in NAION may be due to the SVD. There were significant differences between uninvolved eyes and normal eyes both in short and long PLD MRI imaging, and long PLD indicated the potential compensation ability in ischemia and short PLD indicated the earlier status of ischemia. The cause of the results speculated that patients with NAION may have cerebral SVD, and the uninvolved eyes could keep the compensation of BF perfusion, while the normal population does not have SVD, and there was no chronic ischemia occur, so there are differences between the two groups.

\section{Study limitations}

Our study utilized a retrospective design and was limited to a single center. Stringent inclusion criteria also limited our sample size to 25 patients which may have underpowered some aspects of the study. Because of the retrospective nature of the study, we could not achieve uniform ASL acquisition at a set time point. Delay between symptoms 
and inclusion in the study in NAION patients. Additionally, an admission rate bias for patients in whom ASL was performed may have prevented us from having patients with comparable illness severity. The possibility of a measurement bias for imaging is also likely present in any instance of manual measurement.

\section{Conclusions}

We found that abnormal hemodynamics of cerebral SVD existed prior to the onset of NAION. This suggests an underlying pathogenic mechanism for NAION involving transient insufficiency in blood supply and decompensation of ocular vascular regulation.

\section{Acknowledgments}

Thank you MedEditing (www.medediting.com) for the English language editing service.

Funding: This work is supported by the Project as follow: the National Natural Science Foundation of China (No. 81800840); the Capital Health Research and Development of Special (No. 2018-1-2021).

\section{Footnote}

Conflicts of Interest: All authors have completed the ICMJE uniform disclosure form (available at http://dx.doi. org/10.21037/qims-20-699). The authors have no conflicts of interest to declare.

Ethical Statement: This study was approved by the BFH Ethics Committee and was conducted following the latest iteration of the Declaration of Helsinki (version: 2019-P2201-01). Participants were given written informed consent (version V1.1/2019-09-16) before inclusion in the study.

Open Access Statement: This is an Open Access article distributed in accordance with the Creative Commons Attribution-NonCommercial-NoDerivs 4.0 International License (CC BY-NC-ND 4.0), which permits the noncommercial replication and distribution of the article with the strict proviso that no changes or edits are made and the original work is properly cited (including links to both the formal publication through the relevant DOI and the license). See: https://creativecommons.org/licenses/by-nc-nd/4.0/.

\section{References}

1. Miller NR, Arnold AC. Current concepts in the diagnosis, pathogenesis and management of nonarteritic anterior ischaemic optic neuropathy. Eye (Lond) 2015;29:65-79.

2. Bernstein SL, Miller NR. Ischemic optic neuropathies and their models: disease comparisons, model strengths and weaknesses. Jpn J Ophthalmol 2015;59:135-47.

3. Hattenhauer MG, Leavitt JA, Hodge DO, Grill R, Gray DT. Incidence of nonarteritic anterior ischemic optic neuropathy. Am J Ophthalmol 1997;123:103-7.

4. Jacobson DM, Vierkant RA, Belongia EA. Nonarteritic anterior ischemic optic neuropathy. A case-control study of potential risk factors. Arch Ophthalmol 1997;115:1403-7.

5. Hayreh SS, Joos KM, Podhajsky PA, Long CR. Systemic diseases associated with nonarteritic anterior ischemic optic neuropathy. Am J Ophthalmol 1994;118:766-80.

6. Ing EB, Kam JWK, Cheng JZ, Wong SWK, Strungaru H, Slomovic A, Weisbrod L, Torun N. Incidence of nonarteritic ischemic optic neuropathy following topical clear corneal cataract surgery: survey and meta-analysis. Can J Ophthalmol 2020;55:87-92.

7. Yang HK, Park SJ, Byun SJ, Park KH, Kim JW, Hwang JM. Obstructive sleep apnoea and increased risk of non-arteritic anterior ischaemic optic neuropathy. Br J Ophthalmol 2019;103:1123-8.

8. Biousse V, Newman NJ. Ischemic Optic Neuropathies. N Engl J Med 2015;373:1677.

9. Yang HK, Park SJ, Byun SJ, Park KH, Hwang JM. Risk of Nonarteritic Anterior Ischemic Optic Neuropathy After Cataract Surgery. Am J Ophthalmol 2019;207:343-50.

10. Cestari DM, Gaier ED, Bouzika P, Blachley TS, De Lott LB, Rizzo JF, Wiggs JL, Kang JH, Pasquale LR, Stein JD. Demographic, Systemic, and Ocular Factors Associated with Nonarteritic Anterior Ischemic Optic Neuropathy. Ophthalmology 2016;123:2446-55.

11. Hayreh SS, Zimmerman MB, Podhajsky P, Alward WL. Nocturnal arterial hypotension and its role in optic nerve head and ocular ischemic disorders. Am J Ophthalmol 1994;117:603-24.

12. Arnold AC, Costa RM, Dumitrascu OM. The spectrum of optic disc ischemia in patients younger than 50 years (an Amercian Ophthalmological Society thesis). Trans Am Ophthalmol Soc 2013;111:93-118.

13. Kaup M, Plange N, Arend KO, Remky A. Retrobulbar haemodynamics in non-arteritic anterior ischaemic optic 
neuropathy. Br J Ophthalmol 2006;90:1350-3.

14. Berry S, Lin WV, Sadaka A, Lee AG. Nonarteritic anterior ischemic optic neuropathy: cause, effect, and management. Eye Brain 2017;9:23-8.

15. Lee YC, Wang JH, Huang TL, Tsai RK. Increased Risk of Stroke in Patients With Nonarteritic Anterior Ischemic Optic Neuropathy: A Nationwide Retrospective Cohort Study. Am J Ophthalmol 2016;170:183-9.

16. Park SJ, Yang HK, Byun SJ, Park KH, Hwang JM. Risk of Stroke After Nonarteritic Anterior Ischemic Optic Neuropathy. Am J Ophthalmol 2019;200:123-9.

17. Lee YC, Tsai RK. Risk of Stroke After Nonarteritic Anterior Ischemic Optic Neuropathy. Am J Ophthalmol 2019;203:118-9.

18. Kim MS, Jeong HY, Cho KH, Oh SW, Byun SJ, Woo SJ, Yang HK, Hwang JM, Park KH, Kim CK, Park SJ. Nonarteritic anterior ischemic optic neuropathy is associated with cerebral small vessel disease. PLoS One 2019; 14:e0225322.

19. Wardlaw JM, Smith C, Dichgans M. Mechanisms of sporadic cerebral small vessel disease: insights from neuroimaging. Lancet Neurol 2013;12:483-97.

20. van Norden AG, de Laat KF, Gons RA, van Uden IW, van Dijk EJ, van Oudheusden LJ, Esselink RA, Bloem BR, van Engelen BG, Zwarts MJ, Tendolkar I, Olde-Rikkert MG, van der Vlugt MJ, Zwiers MP, Norris DG, de Leeuw FE. Causes and consequences of cerebral small vessel disease. The RUN DMC study: a prospective cohort study. Study rationale and protocol. BMC Neurol 2011;11:29.

21. Wang H, Meng ZY, Li SG, Wang JJ, Sun J, Li HY. Macular evaluation of the retinal and choroidal vasculature changes in anterior ischemic optic neuropathy-a case control study. BMC Ophthalmol 2018;18:341.

22. Emeterio Nateras OS, Harrison JM, Muir ER, Zhang Y, Peng Q, Chalfin S, Gutierrez JE, Johnson DA, Kiel JW, Duong TQ. Choroidal blood flow decreases with age: an MRI study. Curr Eye Res 2014;39:1059-67.

23. Vaghefi E, Kauv K, Pan W, Squirrell D. Application of Arterial Spin Labelling in Detecting Retinal Ischemia. Case Rep Ophthalmol 2017;8:545-57.

24. Hayreh SS, Zimmerman B. Visual field abnormalities in nonarteritic anterior ischemic optic neuropathy: their pattern and prevalence at initial examination. Arch Ophthalmol 2005;123:1554-62.

25. Hunder GG, Bloch DA, Michel BA, Stevens MB, Arend WP, Calabrese LH, et al. The American College of Rheumatology 1990 criteria for the classification of giant cell arteritis. Arthritis Rheum 1990;33:1122-8.
26. Sanjari MS, Falavarjani KG, Mehrabani M, Ghiasian L, Zamani B. Retrobulbar haemodynamics and carotid wall thickness in patients with non-arteritic anterior ischaemic optic neuropathy. Br J Ophthalmol 2009;93:638-40.

27. Fu Z, Li H, Wang W, Wang Y. Research on Association of the Diameter of the Internal Carotid Artery Siphon and Nonarteritic Anterior Ischaemic Optic Neuropathy. J Ophthalmol 2019;2019:7910602.

28. Riva CE, Hero M, Titze P, Petrig B. Autoregulation of human optic nerve head blood flow in response to acute changes in ocular perfusion pressure. Graefes Arch Clin Exp Ophthalmol 1997;235:618-26.

29. Jelic S, Padeletti M, Kawut SM, Higgins C, Canfield SM, Onat D, Colombo PC, Basner RC, Factor P, LeJemtel TH. Inflammation, oxidative stress, and repair capacity of the vascular endothelium in obstructive sleep apnea. Circulation 2008;117:2270-8.

30. Hayreh SS, Piegors DJ, Heistad DD. Serotonin-induced constriction of ocular arteries in atherosclerotic monkeys. Implications for ischemic disorders of the retina and optic nerve head. Arch Ophthalmol 1997;115:220-8.

31. Witkowska KJ, Bata AM, Calzetti G, Luft N, Fondi K, Wozniak PA, Schmidl D, Bolz M, Popa-Cherecheanu A, Werkmeister RM, Garhöfer G, Schmetterer L. Optic nerve head and retinal blood flow regulation during isometric exercise as assessed with laser speckle flowgraphy. PLoS One 2017;12:e0184772.

32. Dervenis N, Harris A, Coleman AL, Wilson MR, Founti P, Yu F, Siesky B, Anastasopoulos E, Pappas T, Koskosas A, Kilintzis V, Topouzis F. Factors associated with nonactive retinal capillary density as measured with Confocal Scanning Laser Doppler Flowmetry in an elderly population: the Thessaloniki Eye Study (TES). Br J Ophthalmol 2020;104:1246-53.

33. Barakat E, Ginat DT. Magnetic resonance imaging (MRI) features of cataracts in pediatric and young adult patients. Quant Imaging Med Surg 2020;10:428-31.

34. Su T, Yuan Q, Liao XL, Shi WQ, Zhou XZ, Lin Q, et al. Altered intrinsic functional connectivity of the primary visual cortex in patients with retinal vein occlusion: a resting-state fMRI study. Quant Imaging Med Surg 2020;10:958-69.

35. Corno S, Giani L, Laganà MM, Baglio F, Mariani C, Pantoni L, Lovati C. The brain effect of the migraine attack: an ASL MRI study of the cerebral perfusion during a migraine attack. Neurol Sci 2018;39:73-4.

36. Khanal S, Turnbull PRK, Vaghefi E, Phillips JR. Repeatability of Arterial Spin Labeling MRI in Measuring 
Blood Perfusion in the Human Eye. J Magn Reson Imaging 2019;49:966-74.

37. Zhang Y, Harrison JM, Nateras OS, Chalfin S, Duong TQ. Decreased retinal-choroidal blood flow in retinitis pigmentosa as measured by MRI. Doc Ophthalmol 2013;126:187-97.

38. Cohen AD, Agarwal M, Jagra AS, Nencka AS, Meier TB, Lebel RM, McCrea MA, Wang Y. Longitudinal Reproducibility of MR Perfusion Using 3D Pseudocontinuous Arterial Spin Labeling With Hadamard-Encoded Multiple Postlabeling Delays. J Magn Reson Imaging 2020;51:1846-53.

39. Arnold AC. Pathogenesis of nonarteritic anterior ischemic

Cite this article as: $\mathrm{Li} \mathrm{H}$, Sun J, Wang H, Wang Y, Wang Z, $\mathrm{Li} \mathrm{J}$. Evaluation of hemodynamic changes in nonarteritic anterior ischemic optic neuropathy using multimodality imaging. Quant Imaging Med Surg 2021;11(5):1932-1945. doi: 10.21037/qims-20-699 optic neuropathy. J Neuroophthalmol 2003;23:157-63.

40. Patel HR, Margo CE. Pathology of Ischemic Optic Neuropathy. Arch Pathol Lab Med 2017;141:162-6.

41. Hasanreisoglu M, Robenshtok E, Ezrahi D, Stiebel-Kalish $H$. Do patients with non-arteritic ischemic optic neuritis have increased risk for cardiovascular and cerebrovascular events? Neuroepidemiology 2013;40:220-4.

42. Foster RC, Bhatti MT, Crum OM, Lesser ER, Hodge DO, Klaas JP, Chen JJ. Stroke Rate, Subtype, and Cardiovascular Risk Factors in Nonarteritic Anterior Ischemic Optic Neuropathy: A Population-Based Study. J Neuroophthalmol 2020;40:328-32. 